\section{NARX-NN MODEL OF 2-DOF ROBOT ARM DYNAMICS DRIVEN BY FLUIDIC MUSCLES}

MONIKA TROJANOVA, ALEXANDER HOSOVSKY

Technical University of Kosice, Faculty of Manufacturing Technologies with the Seat in Presov, Slovakia

DOI : 10.17973/MMSJ.2019_12_2019016

monika.trojanova@tuke.sk

The article contains the results of identification of manipulator arm dynamics that is driven by pneumatic artificial muscles (specifically, fluidic muscles). The NARX architecture model - a multilayer perceptron network (MLP model) was selected for identification. Simulations were realized using MATLAB, especially with use the System Identification Toolbox. The simulation results were tracked at 3 different delays for the upper and lower axis of the manipulator separately. The NRMSE criterion (Normal Root Mean Square Error) serves to compare simulation results by comparing output of simulations and measured output data.

KEYWORDS

Fluidic Muscles, Planar Robotic Arm, Identification, NARX (Nonlinear Autoregressive Exogenous), MLP (Multilayer Perceptron Network), System Identification Toolbox

\section{INTRODUCTION}

The system represents complex and mutual interconnection of elements that have different parameters and characteristics. By analysing these relationships and characteristics, it is possible to achieve a higher degree of system optimization, respectively its management [Tangirala 2015]. This serves to identification of the system where the model is the basic tool. The model must represent the system in the most appropriate way. As the data presented in the article are measured from the real manipulator, the empirical approach for was chosen identification from two ways of identification. [Balátě 2003], in his literature, presents the advantage of an empirical approach to identification in experimental possibilities, such as:

- artificial introduction of operating conditions;

- artificial introduction of emergency state;

- examining system behaviour in model mode (system is not compromised).

The identification that is described in this article concerns the robotic arm with two degrees of freedom. The authors of the article deal with unconventional drives (if compared to electric or hydraulic drives) that could be applied in the industry, so they have chosen for this device fluid muscles as drive. The researched system, like most systems applied in practice, is nonlinear and dynamic, making it more difficult to identify. The presence of friction, hysteresis, non-linearity of properties is some of the disadvantages [FESTO 2017], that influence the process of identification and management.

Despite the disadvantages of these drives, the pneumatic artificial muscles have several advantages (high flexibility, tensile strength, but also safety) that stimulate researchers to explore this area of drives. The results of the studies that were about the static and dynamic properties of artificial muscles, their models, and the application of models in kinematic systems are described in literature [Hošovský 2016, Sárosi 2015, Zhao 2015, Pitel' 2014, Wickramatunge 2009, Hildebrandt 2005]. Articles that are similar to this research and article (identification of systems powered by pneumatic artificial muscles) are also analysed in [Anh 2006, 2008, 2010]

Fig. 1 shows the structure of the simulation model, the research of which is described in this article. Its input was measured voltage $U$ and its output was differential pressure $\Delta p$. Since the model contains one input and one output, it is a SISO system. In the experimental manipulator, the upper axis represented one SISO system and the lower axis the second SISO system.

However, if we want to look at the manipulator as a whole and we take into account that the pressure differential affects the simulation results also, it is necessary to perform simulations on the MISO model. The structure of this model is shown in Fig.2 and will consist of one SISO system and one MISO system. This means that from the simulated SISO models presented in this article will select the best models whose structure will be used in future research - MISO simulations.

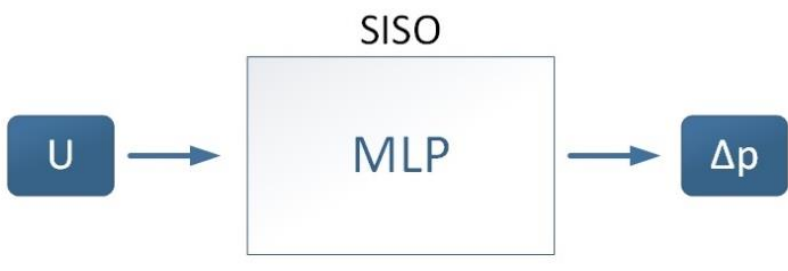

Figure 1: Structure of the simulation model SISO

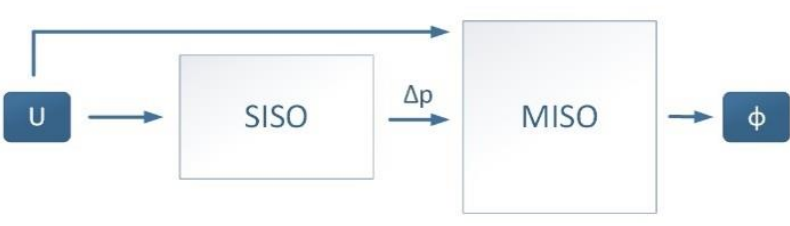

Figure 2: Structure of the next simulation model MISO

The description of the experimental manipulator, the nonlinear model chosen for identification (MLP model), the data obtained, as well as the results of the simulations themselves (from SISO systems), are described in the following sections.

\section{2-DOF PLANAR ROBOTIC ARM}

Fig. 3 shows a 2-DOF robotic arm that was the object of the study. The drive of robotic system is made with two pairs of fluid muscles from the FESTO manufacturer (diameter $20 \mathrm{~mm}$, length $250 \mathrm{~mm}$ ) type MAS - i.e., ends for screwing. The working medium of the muscles is compressed air, which is produced and supplied by the FIAC LEONARDO compressor. When filled with pressurized air, each of the muscle contracts and develop a tensile force. As the manipulator has two joints, gears and chains, the tensile force is transmitted as a torque. In the end, this is reflected by the displacement of the load placed at the end of one of the arms (rotational motion). Therefore, the resulting monitored parameter is the angle of rotation of the joint (Kubler 3610 incremental encoder). The entire arm is attached to the upper base of the metal structure. The electronic pressure regulators Matrix EPR50, incorporating pressure sensors also, are used to detect pressure in the muscles. Each 
muscle has its own pressure regulator. MATLAB/Simulink software was used for data acquisition and identification [Trojanová 2018].

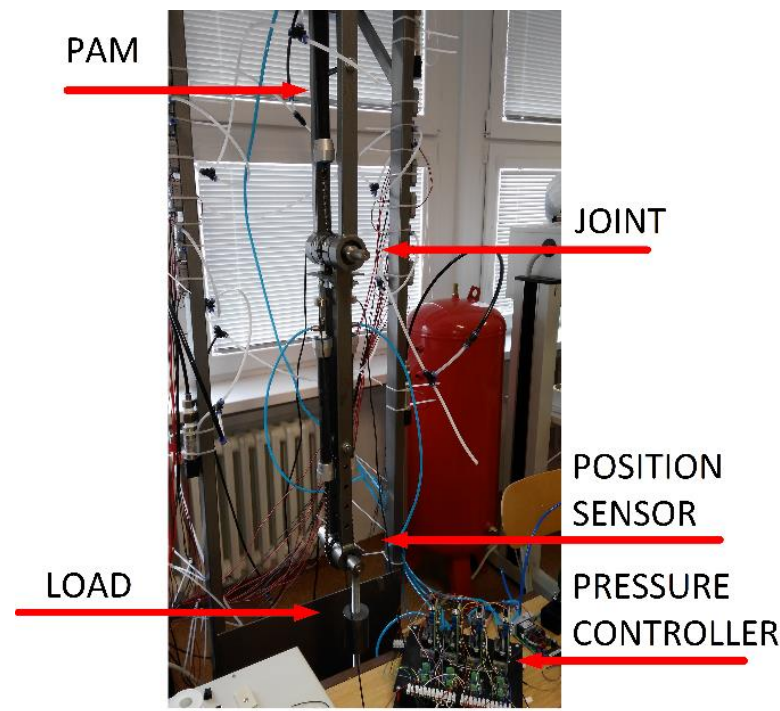

Figure 3: 2-DOF robot arm driven by fluidic muscles

The choice of FESTO's fluidic muscles implemented in the manipulator was for the benefits it brings. In particular, the elimination of dry friction between the outer and inner layers of the muscle (since both layers are combined in one for FESTO muscles), the possibility of application to adverse working conditions, high tensile strength and others [FESTO 2017].

\section{MULTILAYER PERCEPTRON NETWORK}

Since the system - manipulator with PAMs appeared to be nonlinear, it was chosen to identify the model of the multilayer perceptron network (MLP model) - it is shown in Fig. 4 [Nelles 2001, Trojanová 2019]. This model is one of the most well-known and most widely used type of non-linear architecture in the artificial neural network. It is created by linking perceptrons (name for MLP neuron) placed on the hidden layer (one or more), that are connected to the neuron located on the output layer. The task of the perceptrons is to process the inputs $u j$, which have their weight $w_{i j}$ and are located on the input layer, to the output $\mathrm{y}$ with the weight $w_{\mathrm{j}}$ located on the output layer (Eq. (1)) [Nelles 2001, Karray 2004].

$$
y=\sum_{i=0}^{M} w_{i} \varphi_{i}\left(\sum_{j=0}^{p} w_{i j} u_{j}\right)
$$

The processing is made using the $\phi_{1}$ activation function (the most common logistic function (Eq. (2) and the hyperbolic tangent (Eq. (3)). While the hidden layer's parameters are nonlinear, the network output itself is already linear.

$$
\begin{gathered}
\varphi_{i}=\operatorname{logistic}(x)=\frac{1}{1+\exp (-x)} \\
\varphi_{i}=\operatorname{tauh}(x)=\frac{1-\exp (-2 x)}{1+\exp (-2 x)}
\end{gathered}
$$

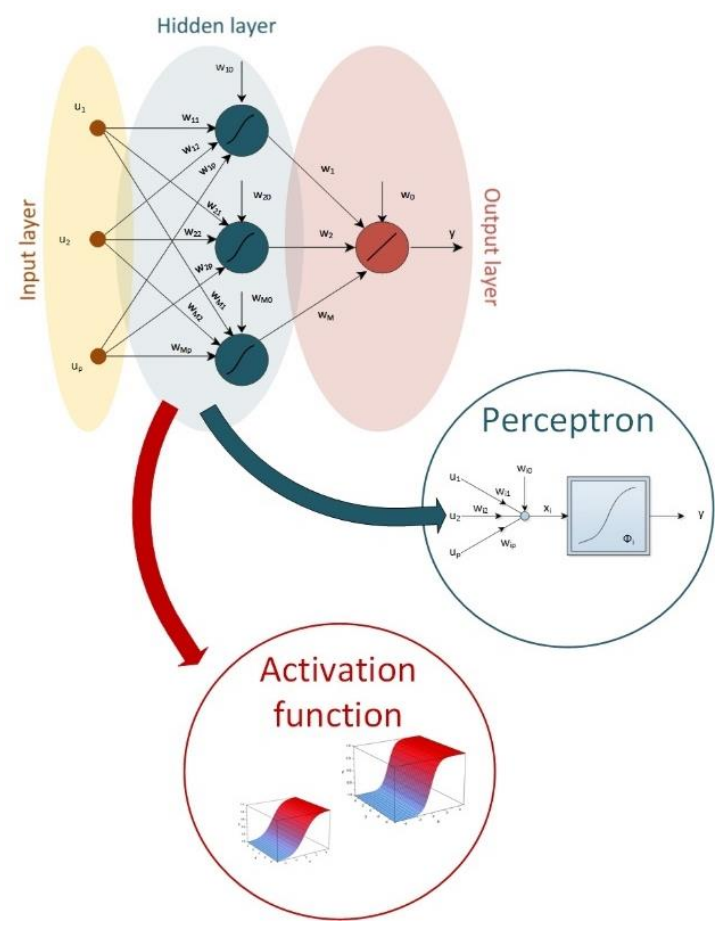

Figure 4: Scheme structure of the Multilayer Perceptron Network

\section{INPUT AND OUTPUT MEASURED DATA}

The input and output data needed for identification were obtained by measurements. Separately were measured data for upper and lower axis (two separate SISO systems), where was observed Voltage $(U)$ at the input, and at the output were monitored the differences of pressures $(\Delta p)$ and the angle of rotation $(\varphi)$. For the training simulation phase were obtained total 28,000 samples, for testing 10,000 samples - in both sets with a sampling period of $3 \mathrm{~ms}$. To generate the training data APRBS signal in the range of -8 to $8 \mathrm{~V}$ was used (Fig. 5 , blue curve, Fig. 6 , green curve). The test data was generated by trapezoidal excitation signals in the range of -6 to $6 \mathrm{~V}$ (Fig. 5 red curve, Fig. 6 , orange curve).

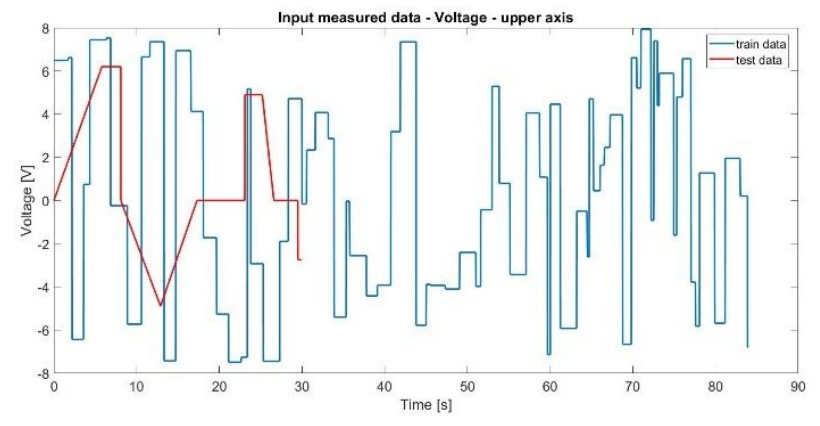

Figure 5: Time dependence of input voltage - upper axis

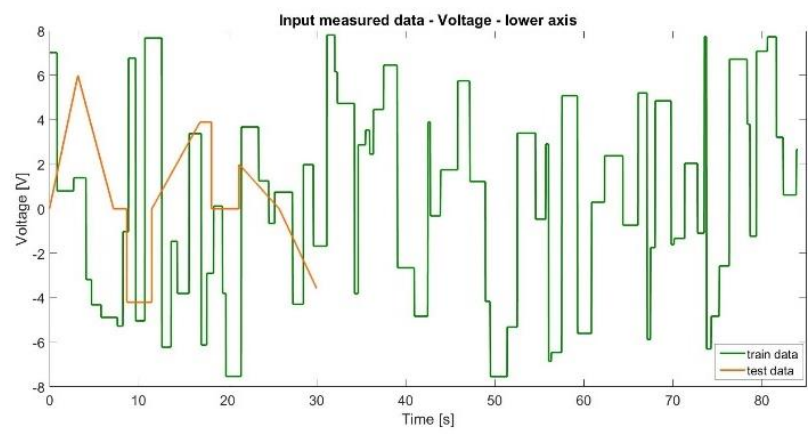

Figure 6: Time dependence of input voltage - lower axis 
The difference of pressures in the muscles (as one of the monitored outputs) was sensed by the pressure sensors, and the measurement results can be seen in Fig. 7 and Fig. 8. The range of difference pressure (depending to the axis) was changing for training from $-580 \mathrm{kPa}$ to $600 \mathrm{kPa}$; for testing in range from -315 $\mathrm{kPa}$ to $450 \mathrm{kPa}$.

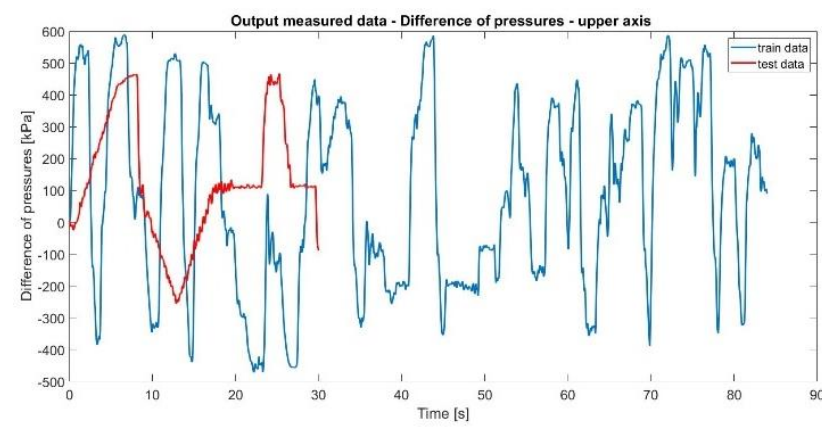

Figure 7: Time dependence of output difference of pressures - upper axis

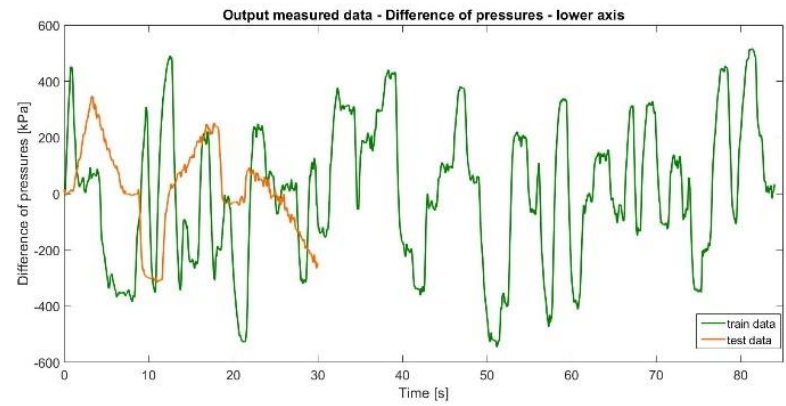

Figure 8: Time dependence of output difference of pressures - lower axis

The most important variable - the angle of rotation - was measured by an incremental sensor. The output data measured for the upper and lower axes as well as for the training and testing phases are shown in Fig. 9 and Fig. 10.

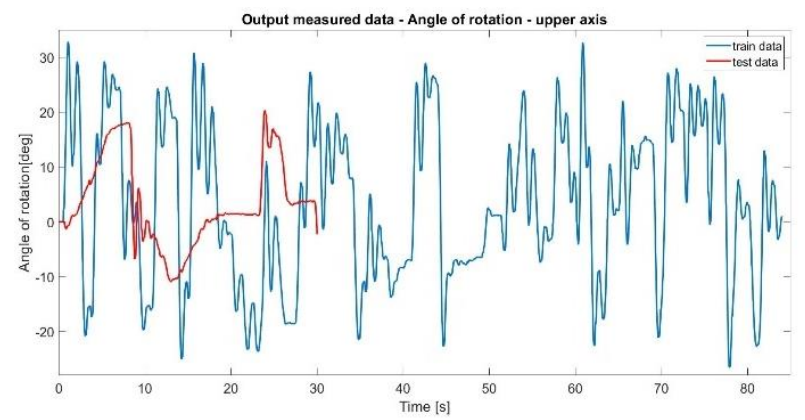

Figure 9: Time dependence of output angle of rotation - upper axis

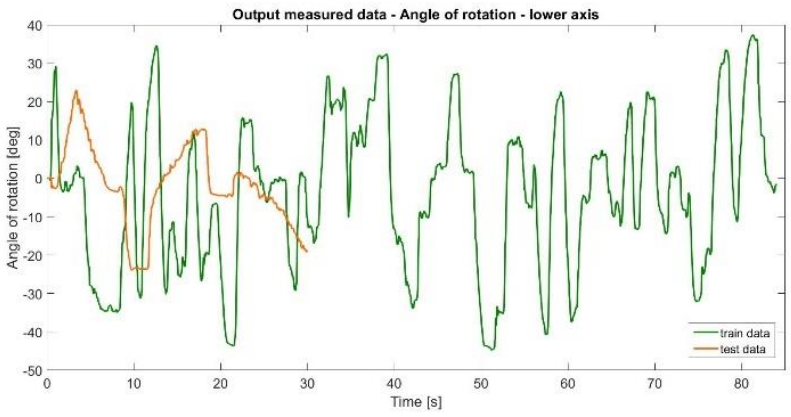

Figure 10: Time dependence of output angle of rotation - lower axis

The data obtained from the measurements were modified in MATLAB - normalized by the command mapminmax to the interval $\langle-1 ; 1\rangle$. After this adjustment, they were imported into the System Identification Toolbox, where was identified the $U / \phi$ dependence separately for the upper and lower axes, but also the $U / \Delta p$ dependence. The simulation results were compared based on Goodness of Fit $\left(F_{g o f}\right)$, whose mathematical formula is expressed by the Eq. 4. The criterion compares the output of the system with the output of the model, where $N$ means the number of samples, $y(n)$ output of the system on the k-th sample and $\bar{y}(n)$ output of the model on the k-th sample.

$$
F_{\text {gof }}=\left(1-\frac{\sqrt{\sum_{k=1}^{N}[y(n)-\hat{y}(n)]^{2}}}{\sqrt{\sum_{k=1}^{N}\left[y(n)-\frac{1}{N} \sum_{k=1}^{N} y(n)\right]^{2}}}\right) x 100 \%
$$

\section{RESULTS OF SIMULATIONS IN SYSTEM IDENTIFICATION TOOLBOX}

In the System Identification Toolbox were set the parameters of the MLP model before the simulation (their overview is shown in Tab. 1). The block diagram of the nonlinear model architecture shown in the toolbox is illustrated in Fig. 11. The basic parameters for such an architecture are inputs $u$, system's outputs $y$, and model outputs $\bar{y}$. In this case, the architecture encompasses a linear and nonlinear block. Identified models differ mainly in the number of neurons used, the type of neural network, the number of inputs $u$ and outputs $y$.

Table 1: Overview of initialization parameters in System Identification Toolbox

\begin{tabular}{|cc|}
\hline \multicolumn{2}{|c|}{ Parameters } \\
\hline Delay & 40 samples \\
\hline No. of terms u1 & $2,3,4$ samples \\
\hline No. of terms y1 & $2,3,4$ samples \\
\hline Nonlinearity & wavelet, sigmoid \\
\hline Number of neurons & 1 and 10 \\
\hline Training algorithm & Gauss - Newton algorithm \\
\hline Number of iterations & 20 iterations \\
\hline
\end{tabular}

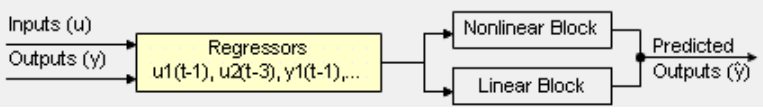

Figure 11: Architecture of nonlinear models in System Identification Toolbox

Table 2: Overview of simulation results for upper axis

\begin{tabular}{|c|c|c|c|c|c|c|}
\hline $\begin{array}{c}\text { Upper } \\
\text { axis } \\
\text { U/ } \phi\end{array}$ & Delay & $\begin{array}{c}\text { No. of } \\
\text { terms } \\
\mathrm{u}\end{array}$ & $\begin{array}{c}\text { No. of } \\
\text { terms } \\
\mathrm{y}\end{array}$ & $\begin{array}{c}\text { Number } \\
\text { of } \\
\text { neurons }\end{array}$ & Nonlinearity & $\begin{array}{c}\text { Fgof } \\
{[\%]}\end{array}$ \\
\hline nlarx1 & 40 & 2 & 2 & 1 & sigmoid & 64,78 \\
\hline nlrax6 & 40 & 3 & 3 & 10 & sigmoid & 57,79 \\
\hline nlrax10 & 40 & 4 & 4 & 10 & sigmoid & 61,76 \\
\hline $\begin{array}{c}\text { Upper } \\
\text { axis }\end{array}$ & Delay & $\begin{array}{c}\text { No. of } \\
\text { terms } \\
\text { U/ } \Delta \mathrm{p}\end{array}$ & $\begin{array}{c}\text { No. of } \\
\text { terms } \\
\mathrm{y}\end{array}$ & $\begin{array}{c}\text { Number } \\
\text { of }\end{array}$ & Nonlinearity & $\begin{array}{c}\text { Fgof } \\
{[\%]}\end{array}$ \\
\hline nlarx15 & 40 & 2 & 2 & 1 & wavelet & 76,80 \\
\hline nlrax19 & 40 & 3 & 3 & 1 & wavelet & 75,04 \\
\hline nlarx21 & 40 & 4 & 4 & 1 & sigmoid & 75,18 \\
\hline
\end{tabular}




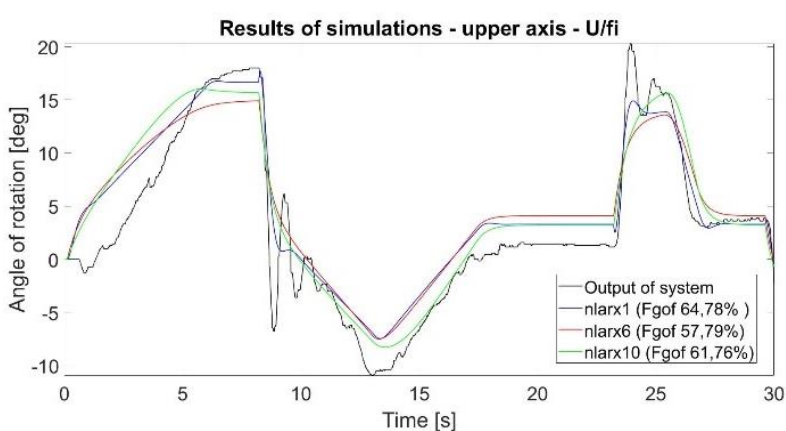

Figure 12: The best models from identification upper axis - $U / \varphi$

Based on the results, the best model was selected for each of the axes. Because the best models will continue to work on further simulations (MISO identification), the data will remain normalized, so the results of the $F_{\text {gof }}$ parameter are for normalized data. A summary of the best simulation results for upper axis (dependence $U / \Delta p$ and $U / \varphi$ ) is given in Tab. 2 .

Fig. 12 shows the time dependence of the angle of rotation for the 3 best simulation models. Fig. 13 shows the time dependence of the pressure difference in the muscles also for the 3 best models for the upper axis. In both cases the output curves of the models are color-coded (blue - 2 delays, red - 3 delays, green -4 delays), the output of the system is marked with a black curve.

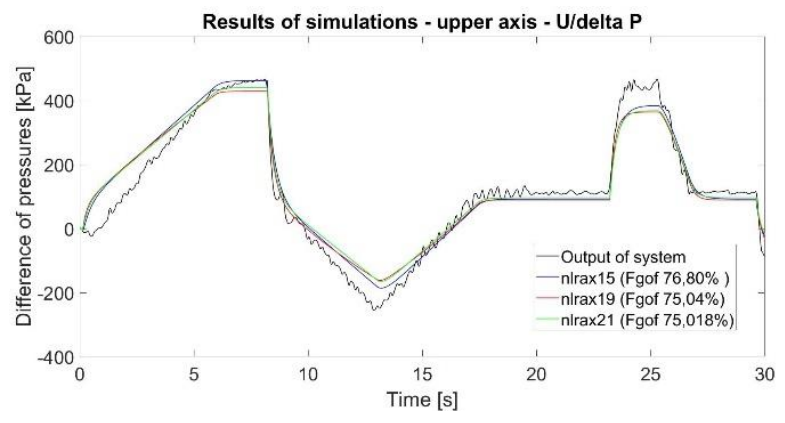

Figure 13: The best models from identification upper axis - $U / \Delta p$

For the lower axis, the results of the identifications are summarized in Tab. 3 for both dependencies. In Fig. 14 and Fig. 15 can be seen a graphical interpretation of simulation outputs, where are again selected the best three models for each dependence. Colour curve interpretation is the same as for the upper axis.

Table 3: Overview of simulation results for lower axis

\begin{tabular}{|c|c|c|c|c|c|c|}
\hline $\begin{array}{l}\text { Lower } \\
\text { axis } \\
U / \phi\end{array}$ & Delay & $\begin{array}{c}\text { No. of } \\
\text { terms } \\
\mathrm{u}\end{array}$ & $\begin{array}{c}\text { No. of } \\
\text { terms } \\
y\end{array}$ & $\begin{array}{c}\text { Number } \\
\text { of } \\
\text { neurons }\end{array}$ & Nonlinearity & $\begin{array}{c}\text { Fgof } \\
\text { [\%] }\end{array}$ \\
\hline nlarx4 & 40 & 2 & 2 & 10 & wavelet & 74,58 \\
\hline nlrax6 & 40 & 3 & 3 & 10 & sigmoid & 82,83 \\
\hline nlrax10 & 40 & 4 & 4 & 10 & sigmoid & 79,71 \\
\hline $\begin{array}{l}\text { Lower } \\
\text { axis } \\
U / \Delta p\end{array}$ & Delay & $\begin{array}{c}\text { No. of } \\
\text { terms } \\
u\end{array}$ & $\begin{array}{c}\text { No. of } \\
\text { terms } \\
y\end{array}$ & $\begin{array}{c}\text { Number } \\
\text { of } \\
\text { neurons }\end{array}$ & Nonlinearity & $\begin{array}{c}\text { Fgof } \\
{[\%]}\end{array}$ \\
\hline nlarx16 & 40 & 2 & 2 & 10 & wavelet & 79,91 \\
\hline nlrax18 & 40 & 3 & 3 & 10 & sigmoid & 74,59 \\
\hline nlarx23 & 40 & 4 & 4 & 1 & wavelet & 76,58 \\
\hline
\end{tabular}

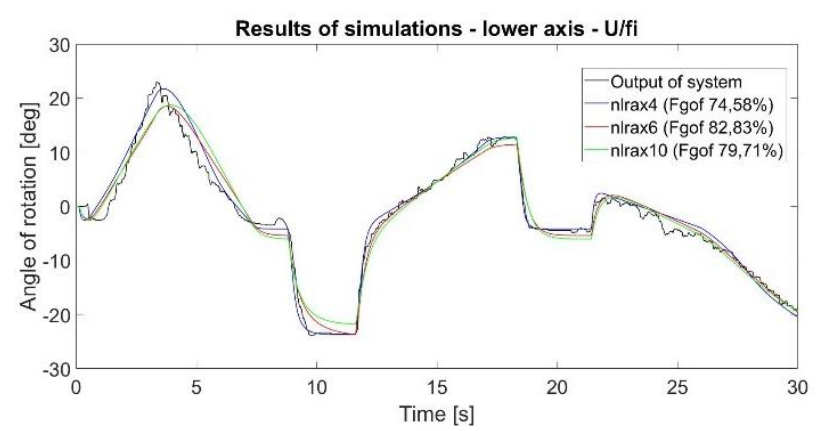

Figure 14: The best models from identification lower axis - $U / \varphi$

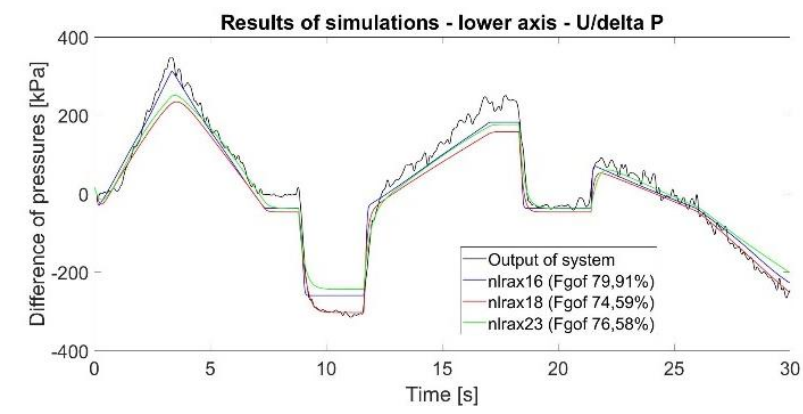

Figure 15: The best models from identification lower axis - $U / \Delta p$

Based on the results interpreted in the last tables, it is possible to state the following:

- it is not dominate only one type of nonlinearity;

- better results were obtained with 1 neuron at the upper axis and for lower axis with the number of neurons 10;

- for both axes, the best results were achieved with two terms in both input and output regressor vectors;

- the upper axis showed greater oscillation, so the results of the $F_{\text {gof }}$ parameter are worse than the lower axis.

\section{CONCLUSIONS}

The main objective of the experimental research described in this article was the identification of two separate SISO systems whose best simulation results serve to identify the MISO system (mentioned in the Introduction). Simulations were implemented in the Matlab software using the System Identification Toolbox. The I / O system was identified using the chosen MLP tool. The results are described in the previous chapter, while the best results are selected for further simulations.

\section{ACKNOWLEDGMENTS}

The research work is supported by grant VEGA 1/0822/16 "Research of Intelligent Manipulator Based on Pneumatic Artificial Muscles with Three Degrees of Freedom"; by grand VEGA 1/0393/18 „Research of Methods for Modeling and Compensation of Hysteresis in Pneumatic Artificial Muscles and PAM-actuated Mechanisms to Improve the Control Performance Using Computational Intelligence" and by EU Structural Funds project with ITMS code: 26220220103.

\section{REFERENCES}

[Anh 2008] Ahn, K.K., Anh, H.P.H. Comparative study of modeling and identification of the pneumatic artificial muscle (PAM) manipulator using recurrent neural networks. Journal of Mechanical Science and Technology, 2008, Issue 22, pp. 12871298. DOI 10.1007/s12206-008-0416-7 
[Anh 2009] Ahn, K.K., Anh, H.P.H. Identification of pneumatic artificial muscle manipulators by a MGA-based nonlinear NARX fuzzy model. Mechatronics, 2009, Vol. 19, Issue 1, pp. 106-133.

[Anh 2006] Ahn, K.K., Anh, H.P.H. System Modeling and Identification the Two-Link Pneumatic Artificial Muscle (PAM) Manipulator Optimized with Genetic Algorithms. In: SICE-ICASE, 2006 Interantional Joint Conference, IEEE, Busan, North Korea, ISBN 89-950038-5-5 98560

[Balátě 2003] Balátě, J. Automatic Control, Praha: Technická literatúra BEN, 2003, ISBN 80-7300-020-2 (in Czech)

[FESTO 2017] Fluidic muscles MAS with screwed joints [online]. June 2018 [date of citing]. https://www.festo.com/cat/sk_sk/data/doc_sk/PDF/SK/MAS_S K.PDF

[Hošovský 2016] Hošovský, A. et al. Dynamic characterization and simulation of two-link soft robot arm with pneumatic muscles. Mechanism and Machine Theory, 2016, Vol. 103, pp. 98-116.

[Hildebrandt 2005] Hildebrandt, A. et al. Cascaded Control Concept of a Robot with Two Degrees of Freedom Driven by Four Artificial Pneumatic Muscle Actuators. In: Proceedings of the 2005 American Control Conference, 2005, pp. 680-685, IEEE, Portland, Oregon.

[Karray 2004] Karray, F.O. and Silva, C. Soft Computing and Intelligent Systems Design: Theory, Tools and Applications. England, Harlow: Addison Wesley, 2004, pp. 584. ISBN 0-32111617-8

[Nelles 2001] Nelles, O. Nonlinear system identification: from classical approaches to neural networks and fuzzy models, Germany, Berlin: Springer, 2001, ISBN 3-540-67369-5
[Pitel' 2014] Pitel', J. and Tóthová, M. Dynamics of pneumatic muscle actuator: measurement and modeling. In: Proceedings of the $15^{\text {th }}$ International Carpathian Control Conference (ICCC 2014), May 28-30, 2014, Danvers: IEEE, pp. 432-436.

[Sárosi 2015] Sárosi J., Pitel' J., Šeminský J. Static Force ModelBased Stiffness Model for Pneumatic Muscle Actuators. International Journal of Engineering Research in Africa, Vol. 18, 2015. pp. 207-214. ISSN 1663-3571

[Tangirala 2015] Tangirala, A.K. Principles of System Identification: Theory and Practice. USA, New York: Taylor \& Francis Group, 2015. s. 881. ISBN 978-1-4398-9602-0

[Trojanová 2018] Trojanová, M. et al. Use of System Identification Toolbox for identification of planar arm dynamics with pneumatic artificial muscles. In: ARTEP 2018, Stará Lesná, Slovakia, February 7-9, 2018, Košice: TUKE, 2018, pp. 02/102/16. ISBN 978-80-553-2914-7

[Trojanová 2019] Trojanová, M. et al. Identification of planar arm dynamics with pneumatic artificial muscles using NARX MLP architecture. In: ARTEP 2019, Stará Lesná, Slovakia, February 6-8, 2019, Košice: TUKE, 2019, pp. 05/1-05/14. ISBN 978-80-553-3250-5 (in Slovak)

[Wickramatunge 2009] Wickramatunge, K.C. and Leephakpreeda, T. Study on mechanical behaviors of pneumatic artificial muscle. International Journal of Engeneering Science, 2009, Vol. 48, Issue 2, pp. 188-189.

[Zhao 2015] Zhao, J., Zhong, J. and Jizhuang, F. Position control of a pneumatic muscle actuator using RBF neural network tuned PID controller. Mathematical Problems in Engineering, 2015, Vol.2015, pp. 1-16.

\section{CONTACTS}

Ing. Monika Trojanová, Assoc. Prof. Ing. Alexander Hošovský, PhD.

Technical University of Košice, Faculty of Manufacturing Technologies with the Seat in Prešov, Department of Industrial Engineering and Informatics, Bayerova 1, 08001 Prešov, Slovakia +421 055602 6420, monika.trojanova@tuke.sk, alexander.hosovsky@tuke.sk, http://www.fvt.tuke.sk 